sulfatases, s'additionnent les symptômes de toutes ces affections, y compris l'ichthyose. Dans cette maladie, les enzymes se synthétisent à un rythme apparemment normal, mais leur dégradation est accélérée par défaut d'un "stabilisateur " commun non encore identifié.

On voit que la stéroïde sulfatase présente de nombreuses facettes. Nous voudrions en ajouter une dernière, touchant à la génétique comparée. Il est admis que les gènes portés par le chromosome $\mathrm{X}$ sont les mêmes chez l'ensemble des mammifères. Or le déficit en STS chez la souris possède une transmission qui semble autosomique dans la plupart des essais de croisement. La question vient d'être tranchée [7] par des expériences croisant des mâles déficients en STS avec des femelles $\mathrm{XO}\left({ }^{1}\right)$ porteuses d'un marqueur cutané lié à l'X. Cónclusion: le gène de la STS est bien porté par l'X. Pour réconcilier ces résultats avec ceux qui militent pour une transmission autosomique, les auteurs suggèrent que le chromosome $\mathrm{Y}$ porte un allèle fonctionnel de la STS qui subit une recombinaison obligatoire avec l'allèle lié à l'X, lors de la fusion des extrémités de $X$ et de $Y$, au cours de la méiose. Cet allèle n'existe apparemment pas sur le chromosome Y chez l'homme.

(1) Chez la souris, la formule XO donne une femelle normale et fertile, alors que dans lespèce humaine elle aboutit à un syndrome de Turner accompagné de stérilité.

I. France JT, Liggins GC. Placental sulfatase deficiency. 7 Clin Endocrinol Metab 1969; 29: I38-4 I.

2. Bedin M, Conquy P, Alsat E, Cédard L. Déficit en sulfatase placentaire. Nouv Presse Med 1976; 5: 1889-92.

3. Shapiro LJ, Weiss R, Webster D, France JT $\mathrm{X}$-linked ichthyosis due to steroid-sulphatase deficiency. Lancet 1978; 1: 70-2.

4. Curry CJR, Magenis RE, Brown M, et al. Inherited chondrodysplasia punctata due to a deletion of the terminal short arm of an $\mathrm{X}$ chromosome. $N$ Engl 7 Med I984; 311: 1010-5.

5. Shapiro L, Mohandas T, Weiss R, Romeo G. Non-activation of an $\mathrm{X}$ chromosome locus in man. Science 1979; 204: $1224-6$.

6. Epstein ES, Bonif as JM. Recessive X-linked ichthyosis: lack of immunologically detectable steroid sulfatase enzyme protein. Hum Genet 1985; 71: $201-5$.

7. Keiges E, Rivest M, Siniscalco M, Gartler SM. X-linkage of steroid sulphatase in the mouse is evidence for a functional $\mathrm{Y}$-linked allele. Nature 1985; 31 5: 226-7.

\section{Réarrangement des gènes codant pour le récepteur des cellules lymphocytaires $T$ au cours des syndromes lymphoprolifératifs}

Le clonage moléculaire du gène codant pour la chaîne $\beta$ du récepteur des lymphocytes $T[1,2]$ a permis en 1984 de faire des progrès essentiels dans la compréhension des phénomènes de différenciation de ces cellules. Le récepteur $\mathrm{T}$ constitue la structure des lymphocytes $\mathrm{T}$ qui est responsable de la reconnaissance spécifique de leurs cibles, de la même manière que les anticorps synthétisés par les lymphocytes $B$ assurent leur spécificité par des antigènes particuliers. Dans les deux cas (celui du récepteur $T$ et des anticorps) des mécanismes de réarrangements géniques sont impliqués dans l'acquisition de cette spécificité et sont à l'origine de la diversité des réponses possibles. Les gènes des immunoglobulines sont ainsi dans une configuration dite "germinale " dans les cellules lymphocytaires non B et sont réarrangés au cours de la différenciation des lymphocytes $\mathrm{B}$.

L'observation de ce réarrangement, dû à la technique de l'hybridation moléculaire sur filtre selon Southern (voir Lexique médecine/sciences $n^{\circ} 2$, vol. 2) permet ainsi d'assurer qu'une population cellulaire (par exemple une prolifération lymphocytaire maligne) est d'origine $\mathrm{B}[3,4]$.

Plus récemment, une série d'articles dont nous ne citerons que quelques exemples $[5,6,7]$ montrent que, parallèlement, les gènes des récepteurs sont presque constamment remaniés dans les proliférations lymphocytaires $\mathrm{T}$ telles les leucémies lymphoblastiques $\mathrm{T}$, leucémies lymphoïdes chroniques $\mathrm{T}$, lymphomes T, syndrome de Sézary, mycosis fungoïdes, etc. Un tel phénomène n'est jamais observé dans des proliférations lymphocytaires $\mathrm{B}$, des maladies de Hodgkin ou d'autres tumeurs et leucémies.

Le réarrangement du gène codant pour le récepteur $T$ est donc un puissant marqueur des proliférations lymphocytaires $\mathrm{T}$ dont il indique en outre qu'elles sont "clonales ", c'est-à-dire que toutes les cellules d'une même tumeur ont le même réarrangement et dérivent donc probablement d'une cellule unique, cible initiale du processus de cancérisation.

A. $\mathbf{K}$.

I. Yanagi $\mathrm{Y}$, Yoshikai $\mathrm{Y}$, Legget $\mathrm{K}$, et al. A human $\mathrm{T}$ cell-specific eDNA clone encodes a protein having extensive homology to immunoglobulin chains. Nature 1984; 308: 145-9.2. Chien YH, Gascoigne NR J, Kavaler J, et al. Somatic recombination in a murine T receptor gene. Nature 1984; 309: 332-6. 3. Korsmeycr SJ, Arnold A, Bakhshi A, et al. Immunoglobulin gene rearrangement and cell surface antigen expression in acute lymphocytic leukemias of T cell and B cell precursor origins. 7. Clin Invest 1983; 71, 301-13.

4. Arnold A, Cossman J, Bakhshi A, et al. Immunoglobulin gene rearrangement as unique clonal markers in human lymphoid neoplasms. $N$ Engl 7 Med 1983; 309: $1593-9$.

5. Toyonaga B, Yanagi $Y$, Suciu-Foca N, et al. Rearrangement of $T$ cell receptor gene $Y T 35$ in human DNA from thymie leukcmia $T$ cell lines and functional $T$ cell clones. Nature 1984; 311 : 385-7. 6. Aisenberg AC, Krontiris TG, Mak TW, el al. Rearrangement of the gene for the $\beta$ chain of the T cell receptor in T cell chronic lymphocytic leukemia and related disorders. $N$ Engl 7 Med 1985, 313: 529-33.

7. Bertness $\mathrm{V}$, Kirch $\mathrm{I}$, Hollis $\mathrm{G}$, et al. $\mathrm{T}$ cell receptor gene rearrangements as clinical markers of human 7. Berthess V, Kirch $N$, Hollis G, et al. T cell receptor 